\title{
Modification of Wastewater Treatment Technology at Cottonseed Oil Plant
}

\author{
Mary Shick Alshabab ${ }^{1}$, Maria Andrianova ${ }^{1, a}$, and Dergham Alsalloum ${ }^{2}$ \\ ${ }^{1}$ Peter the Great Saint-Petersburg State Polytechnic University, 195251, St.Petersburg, Polytechnicheskaya street, \\ 29, Russian Federation
}

${ }^{2}$ Al-Baath University, Homs, Syrian Arab Republic

\begin{abstract}
Wastewaters from cottonseed oil producing plant in Syria were studied in laboratory experiments. Aim of the study was to suggest modification of wastewater treatment technology in order to increase its efficiency. Concentration of pollutants in wastewaters was controlled by measurement of COD. According to the results of experiments it was suggested to decrease significantly (8-20 times) dosages of reagents (acidifier, coagulant, flocculant) in several actual stages of treatment (acidification, separation, coagulation and sedimentation) and add stage of dispersed air flotation before coagulation treatment. The modified wastewater treatment technology would reduce COD to the values allowed for irrigation waters by Syrian National Standard.
\end{abstract}

\section{Introduction}

Application of wastewaters for crops irrigation is important in Eastern Mediterranean where agricultural sector remains the largest water consumer [1, 2, 3]. Among discharges of various industries wastewaters from food production seem to be more suitable for application in agriculture. Due to the natural origin of main components, low toxicity and good biodegradability could be expected for impurities in such wastewaters. According to national water quality standards, wastewaters need treatment before irrigation $[1,2]$.

There is a long tradition in Syria to use wastewater for irrigation. In general, the reuse of wastewater in Syria is largely unplanned and mainly untreated wastewater is used. Wastewater is often taken uncontrolled from sewage channels or polluted rivers [3].

Wastewaters of a vegetable oil company in Syria are studied in this paper. The study was conducted to evaluate efficiency of wastewater treatment technologies and suggest means to improve them in order to meet the requirements of the Syrian National Standard 2752/2003 for crops irrigation waters [5].

The studied company produces mainly cottonseed oil. Water as steam and liquid is used at many stages of oil production [4]. The main impurities in wastewater are organic substances from crude cottonseed oil such as proteins, phospholipids, free fatty acids, hydrocarbons, sterols, pigments and substances that cause unwanted taste and odor [4]. Wastewaters of vegetable oil production have low ratio of biological oxygen demand in 5 days $\left(\mathrm{BOD}_{5}\right)$ to chemical oxygen demand (COD) $[6,7,8]$.

\footnotetext{
${ }^{a}$ Corresponding author : maandrianova@yandex.ru
} 
Organic matter is present in dissolved, colloidal and suspended form. Suspended matter also includes parts of seeds and inorganic matter such as sand, clay, insoluble products formed as a result of reagent treatment [8]. According to these characteristics of impurities wastewater quality at various stages of its treatment can be controlled mainly by measuring concentration of total suspended solids (TSS) and COD. It is also necessary to control $\mathrm{pH}$ because it is an important indicator in different stages of physicochemical treatment.

Several types of technologies and constructions are used in treatment of wastewater from vegetable oil plants. Many of them are also widely applied in treatment of other types of waters. For example, coagulation and filtration are used in treatment of drinking water [9, 10], municipal wastewater [11, 14], drainage water [15], separation and flotation are used in treatment of industrial wastewaters polluted with petroproducts $[10,16,17]$.

In oil wastewaters treatment processes driven by gravity force are applied to remove settling materials (sand, clay, fine gravel) and isolation of free floating oils in separators and settling tanks. Physical chemical methods (coagulation, flotation, etc.) are used to remove finely dispersed material, emulsified oils, and dissolved pollutants. Biological treatment allows removing dissolved pollutants, which can be biologically degraded, such as phenols, aldehydes and others. But it is rarely used in vegetable oils plant wastewaters due to the low value of their $\mathrm{BOD}_{5} / \mathrm{COD}$ ratio [6 - 8]. Additional technologies of treatment (filtration through sand, coal, membrane filtration) are applied in some cases $[6,7,13,18,19]$.

\section{Objects of investigation}

\subsection{Oil production and wastewater generation at the plant}

Al-Ahliah Company for Vegetable Oil Production was studied. It is one of the biggest nutritional oils companies in Syria. The company produces a group of vegetable oils products under several brand names. The most used raw material is cottonseeds. The company is located about $5 \mathrm{~km}$ to the north of the city of Hama. The company occupies area of $200000 \mathrm{~m}^{2}$ where the technological parts of the company occupy $60000 \mathrm{~m}^{2}$, the rest of the area is agricultural land that belongs to the company. The wastewater is treated in order to irrigate the neighbouring lands, which are usually planted with industrial crops.

Process of oil production starts with seeds preparation. Seeds are screened on vibrating sieves to separate sticks and stones. The cotton fluff is also removed. Then cottonseeds are cracked to separate the kernel from the external shell. The kernels are converted to thin flakes which are cooked in boilers equipped with sprinklers. The boilers have double walls to heat the flakes using steam and are equipped with a motor to flip the contents. The purpose of this stage is to eliminate the toxic effects of gossypol [20-21] and to make the mechanical pressing easier.

Cooked flakes release oil and water under mechanical pressing. The resulting liquid mixture is then moved to separation tanks, where the oil floats on surface of water and later is transported to crude oil tanks. The remaining solid material (seed cake) contains about 5-10\% oil, and a solvent (hexane) is added to extract oil from it. The oil-solvent mixture is heated using steam in an extraction device (a double-walled boiler). The mixture is then moved to a distillation tower to separate the oil from the solvent. The solvent is then condensed and collected in tanks, where it floats on the surface of the water and can be separated and used again.

Crude oil treatment is done to remove the maximum amount of undesirable substances from oil. It includes stages of degumming, refining, colour and odour removal. Degumming removes resins, proteins, phosphides which form 1-3\% of crude oil. For this purpose, the process of rehydration is used, by spraying water, steam or acid solutions (often phosphoric acid) on a limited quantity of crude oil at a temperature of $35-50{ }^{\circ} \mathrm{C}$ for several minutes along with slow stirring. A turbid layer is formed on the interphase boundary between the oil and water. Gums precipitate in the water layer. The 
wastewater resulting from this process contains most of the impurities existed in crude oil such as free fatty acids, phosphides (lecithin), sterols, saturated and unsaturated hydrocarbons, glycerine.

During refining alkaline solution (such as sodium hydroxide solution) is added according to the acidity of the oil. Then with stirring and raising the temperature to $70^{\circ} \mathrm{C}$ free fatty acids, phosphides, resins and materials are deposited in the form of sodium salts, in addition absorbing a portion of sterols, waxes and gums in the formed soap stock. Wastewater resulting from this process contains some oil, soda, soap and glycerine.

Colour removal (bleaching) is designed to remove the largest part of oil pigments using adsorbents. The most used substance is a clay material that consists mainly of hydrated aluminium silicate, in the form of a fine powder. The bleaching process takes place in cylindrical devices with a conical bottom, equipped with mixers for flipping the content, under a cooking temperature of $80-90{ }^{\circ} \mathrm{C}$ and with a stirring period between $20-40$ min under normal atmospheric pressure. After that oil is pulled to compressed refineries to get rid of depleted clay material.

Deodorization is done to remove substances that cause the unwanted smell and taste of oil. The oil is placed in cylindrical device, all the air in the devices is vacuumed, steam is passed through the oil under a low pressure $(2-5 \mathrm{mmHg})$ with a working temperature of $200-250^{\circ} \mathrm{C}$. The steam bubbles go through the oil, carrying with it water-soluble chemicals. Wastewater resulting from deodorization carries aldehydes, ketones and free fatty acids with a low molecular weight.

Mechanical filtering is done by compressed refineries to remove the solid impurities suspended in oil. Often the oil goes through two filtering processes: the first after the bleaching process, and the second after the end of all operations. After filtering oil is sent to the last producing section - filling and packing.

The wastewaters from oil production are transported to wastewater treatment plant.

\subsection{Wastewater treatment procedure}

During treatment wastewaters from the cottonseed oil plant underwent the following stages. In the primary separation tank oil fraction was isolated from water fraction. Big drops of oil floated to the surface of separator, some suspended solids settled to its bottom. Oil fraction was sucked by floating pumps and taken to special tanks.

The water after that passed through fine screens (diameter $1.5 \mathrm{~mm}$ ). Wastewater at this stage had alkalic reaction ( $\mathrm{pH}$ between 8.3 and 11.2). After that water was mixed with sulfuric acid to reach $\mathrm{pH} 3$-3.5. In separation tank for acidified water the oily acidified material floated on the surface where it was scraped and pumped to collection tanks.

Before the next stages of treatment water was neutralized with slaked lime in mixing and sedimentation tank. After that reagents for coagulation treatment (polyacrylamide and aluminum sulfate) were added to water and it was then transferred to lamellar settler, where sediments were removed. The final treatment of water was done by sand filters and coal filters. Filtered water was chlorinated and transported to treated water tank.

The problems with wastewater treatment at the studied plant were the following. The process of dosing was not properly controlled. The main operating problem at the plant was the removal of sludge and sediments from the bottom of the tanks, which caused the need to stop the work of the treatment plant from once to while to clean the tanks and sometimes to use air pumps to help in the cleaning operation. The efficiency of the final lamella clarifier was good, but soon it reduced because of the sticky sediments and the difficulty of finding an effective technology to clean the surfaces of the plates. The sludge showed high viscosity which might be imputed to the uncontrolled dosage of polymer.

\subsection{Wastewaters sampling and analysis}

Wastewater samples were collected from the last section of the primary separation tank (after separating the oil from the surface of alkaline wastewater). Two samples of $20 \mathrm{~L}$ each were collected 
in amber glass bottles in June, 2009. The samples were stored in refrigerator for about a week prior to experiments and analyses.

COD was determined in wastewater samples diluted 50-100 times by distilled water. Concentration of potassium dichromate that remained in solution after incubation at high temperature in presence of sulfuric acid was measures by titration with Mohr's salt with indicator ferroin. Measurement error was $\pm 15 \%$. Water $\mathrm{pH}$ was measured by a laboratory $\mathrm{pH}$-meter. Measurement error was $\pm 0.05 \mathrm{pH}$ units.

\section{Results and discussion}

Parameters of wastewater from the studied oil production plant and requirements of Syrian National Standard 2752/2003 are shown in Table 1. The data demonstrates that wastewaters cannot be used for irrigation because of high values of COD (at least decreasing of about 50-200 times is needed), TSS (decreasing of 5-16 times needed) and high $\mathrm{pH}$ value. However the wastewater treatment technology that had been applied at the plant at the period of these experiments also failed to give water enough good quality for irrigation, especially in reduction of COD (data not shown). According to sets of laboratory data from the company $\mathrm{BOD}_{5} / \mathrm{COD}$ was about 0.2 and therefore $\mathrm{COD}$ can be used as a main parameter for wastewater quality control.

Table 1. Selected requirements of Syrian Standard No. 2752/2003 for irrigation and parameters for wastewater from the plant.

\begin{tabular}{|l|c|c|c|c|}
\hline Parameter & $\begin{array}{c}\text { Category A } \\
\text { (Cooked vegetables, } \\
\text { playgrounds, parks } \\
\text { and roadsides in } \\
\text { residential areas) }\end{array}$ & $\begin{array}{c}\text { Category B } \\
\text { (Fruit trees, grain, fodder } \\
\text { crops, green areas and } \\
\text { roadsides outside } \\
\text { residential areas) }\end{array}$ & $\begin{array}{c}\text { Category C } \\
\text { (Forest trees and } \\
\text { industrial crops) }\end{array}$ & $\begin{array}{c}\text { Wastewater } \\
\text { sample from } \\
\text { plant }\end{array}$ \\
\hline $\mathrm{COD}(\mathrm{mg} / \mathrm{l})$ & 75 & 200 & 300 & 14000 \\
\hline $\mathrm{TSS}(\mathrm{mg} / \mathrm{l})$ & 50 & 150 & 150 & 800 \\
\hline $\mathrm{pH}$ & $6-9$ & $6-9$ & $6-9$ & 11 \\
\hline
\end{tabular}

In order to modify the existing treatment procedures laboratory experiments were fulfilled with samples of wastewater. Fig. 1 depicts selected results of wastewater acidification (with $98 \% \mathrm{H}_{2} \mathrm{SO}_{4}$ ) and subsequent removal of free oil in separator. The best treatment was observed at $\mathrm{pH} 2$. For future treatment it was decided to add acid up to $\mathrm{pH} 4$ because the results in the range $\mathrm{pH} 2-4$ were close and within the measurement accuracy. Also this decision was done to save reagents because the dosage of sulfuric acid at low $\mathrm{pH}$ was 20 times more than at $\mathrm{pH}=4$. In general at this stage COD of water decreased by $40-50 \%$.

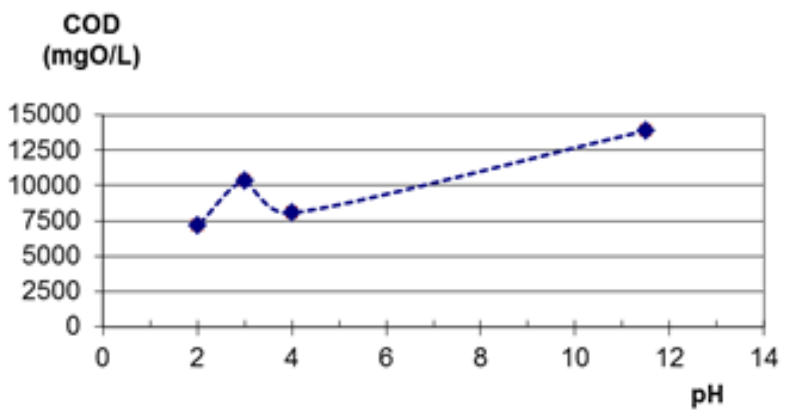

Figure 1. Changing of COD in wastewater after acidification and separation. 
In wastewater treatment, oil-water separators need to be followed by subsequent treatment to remove other forms of oils: mechanical dispersions, chemical emulsions and dissolved oils [18]. After choosing the suitable $\mathrm{pH}$ for acidification it was suggested to use additional stage of treatment flotation. Acidic conditions could be favourable for it due to reduction in electrostatic repulsive forces between dispersed fine oil droplets [20].

In the laboratory experiment, portative aerator producing 1.5-2 L of air per minute was used. The efficiency of flotation of acidified water (without other chemical additives) was tested for different periods. As it is shown in Fig. 2b, flotation successfully decreased concentration of COD in wastewater after collection of froth away from the surface. A flotation period of 15 min provided the best removal efficiency. However, experiments at site should be recommended in order to choose the most effective regime and construction of flotator.

a)

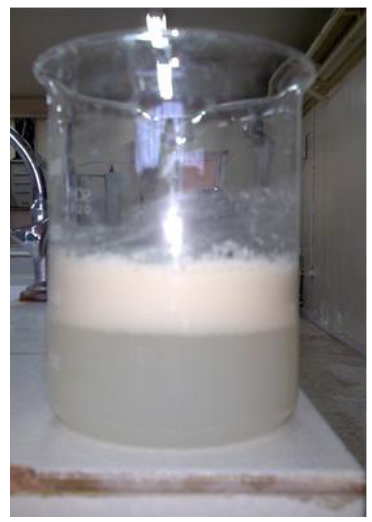

b)

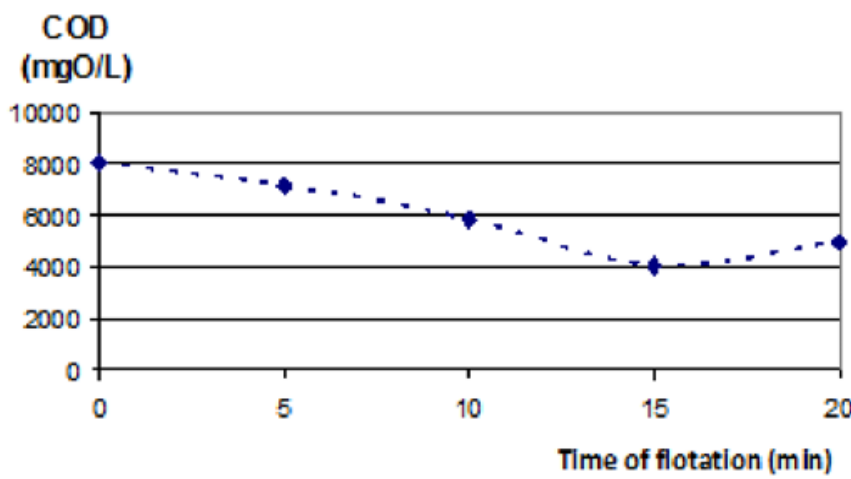

Figure 2. (a) Froth on the surface of wastewater after aeration; (b) Changing of COD in wastewater after various periods of flotation.

The next stage at the plant was coagulation treatment. For effective use of aluminum salts neutral reaction of water is preferable [7,9]. Therefore after flotation $140-200 \mathrm{mg} / \mathrm{L} \mathrm{of} \mathrm{Ca}(\mathrm{OH})_{2}$ was added to wastewater up to $\mathrm{pH} 7-8$. Then coagulant was added at dosage of $4-15 \mathrm{mg} / \mathrm{L}$. After that samples were left for 30 minutes for flocculation and sedimentation. COD was measured in water above the settled sediments. The results in Fig. 3a show that dosage over optimal value could decrease efficiency of treatment. Optimal dosage obtained in laboratory experiments $(4-5 \mathrm{mg} / \mathrm{L}$ of aluminium sulfate) was one order of magnitude lower than dosage used at the plant $(35 \mathrm{mg} / \mathrm{L})$.

a)
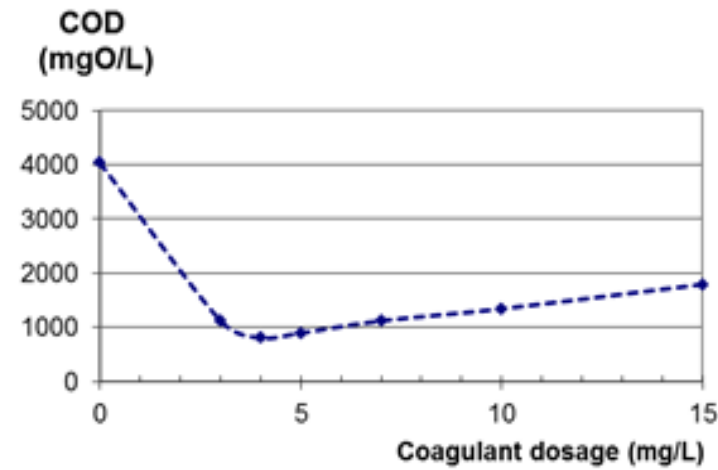

b)

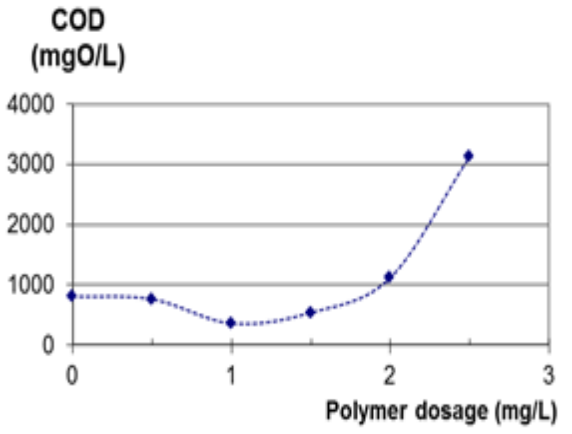

Figure 3. (a) Changing of COD in wastewater after neutralization and treatment with various dosages of aluminium sulfate; (b) Changing of COD in wastewater after neutralization and treatment with various dosages of polymeric flocculant and dosage of coagulant $4 \mathrm{mg} / \mathrm{L}$. 
In the last part of experiment, the influence of flocculant on the efficiency of coagulation treatment was studied. Polymer polyacrylamide was added to neutralized wastewater at dosage $0.5-2.5 \mathrm{mg} / \mathrm{L}$. After that aluminum sulfate was added at dosage of $4 \mathrm{mg} / \mathrm{L}$, and the samples were left for $30 \mathrm{~min}$. The results are shown at Fig. 3b. The optimal dosage of flocculant is about $1 \mathrm{mg} / \mathrm{L}$ and higher values decrease treatment efficiency significantly. Such effect is typical for coagulation treatment, for high concentrations of coagulant and flocculant can stabilize colloidal and suspended matter and hinder water treatment process [13]. It can also be seen from Fig. 3a and Fig. 3b that overdosage of coagulant is less harmful to the treatment process than overdosage of flocculant. Optimal flocculant dose found from experiment was several times lower than dosage actually used at the plant $(20 \mathrm{mg} / \mathrm{L})$.

After all the stages of treatment modelled in the laboratory experiments, COD of wastewater decreased from $14000 \mathrm{mgO} / \mathrm{L}$ to $350 \mathrm{mgO} / \mathrm{L}$. Concentration of chemically oxidized matter in water decreased 40 times and the reached values of COD were very close to the value allowed for irrigation of industrial crops by Syrian National Standard. It can be supposed that filtration of such water through sand and coal filters as it was done at the plant would decrease COD to a level allowed for irrigation.

\section{Conclusions}

Treatment of wastewater at vegetable oil producing plant in Syria was studied. Preliminary monitoring of the wastewater treatment plant showed that dosages of chemical additives were high compared to the recommended values in industrial wastewater treatment. The efficiency of treatment, measured mainly by the COD removal, was not always enough to use the treated water in irrigating the neighbouring agricultural lands.

In order to achieve a COD removal efficiency of about $97 \%$, a series of laboratory experiments was conducted to define the proper dosages of reagents and check efficiency of dispersed air flotation suggested as a new stage of treatment. Based on the results of experiments the following wastewater treatment stages were recommended.

1. alkaline wastewaters $(\mathrm{pH} \mathrm{11)}$ are treated in primary separator where oil floats up and is removed from water fraction,

2. waters are acidified with sulfuric acid to $\mathrm{pH} 4$ and free oil is removed in separator ( $\mathrm{pH} 3-3.5$ was used in actual treatment at the plant),

3. part of remained organic matter is removed from water as froth during dispersed air flotation (this stage is suggested instead of in separation actually used at the plant),

4. water is neutralized by $\mathrm{Ca}(\mathrm{OH})_{2}$ to $\mathrm{pH} 7-8$,

5. water undergoes coagulation treatment with the following dosages: $4 \mathrm{mg} / \mathrm{L}$ of aluminium sulfate $(35 \mathrm{mg} / \mathrm{L}$ was actually used at the plant) and $0.5-1 \mathrm{mg} / \mathrm{L}$ of polyacrylamide $(20 \mathrm{mg} / \mathrm{l}$ was actually used at the plant).

6. subsequent filtration and disinfection.

The suggested modifications of wastewater treatment allow to reduce COD 40 times and reach the values of COD allowed for irrigation by Syrian national Standard 2752/2003.

\section{References}

1. M.Y. Saidam, A regional overview of wastewater management and reuse in the Eastern Mediterranean Region (Regional CEHA, Cairo, Egypt, 2005)

2. A.N. Angelakis, Wastewater Reclamation and Reuse Practices in Mediterranean Region (WHO regional Office for Europe, EURO Project Office, MAP, Athens, Greece, 2002)

3. S. Rothenberger. ACWUA Summary report - Wastewater Reuse in Arab Countries (ACWUA, 2010)

4. O. B. Adelola, E. A. Ndudi. International Journal of Basic and Applied Science, 01, 398-402 (2012)

5. Syrian National Standard No. 2752/2003, Treated wastewater used for irrigation (2003) 
6. N. Azbar, T. Yonar. Process biochemistry 39, 869-875 (2004)

7. K. B. Chipasa. Polish Journal of Environmental Studies 10, 141-147 (2001)

8. S. Aslan, B. Alyüz, Z. Bozkurt, M. Bakaoğlu. Polish Journal of Environtal Studies, 18, 533-538, (2009)

9. Andrianova M. Ju., Molodkina L.M., Chusov A.N. Applied Mechanics and Materials, 587-589, 573-577 (2014)

10. N.I.Vatin, D. Nemova, N. Kharkov. Applied Mechanics and Materials, 680, 354-358 (2014)

11. D.D. Kolosova, A.A. Maslak, N.N. Rolle, L.M. Molodkina. Magazine of Civil Engineering. 6 (41), 22-30 (2013)

12. N. I. Vatin, V. N. Chechevichkin, A. V. Chechevichkin, Ye. S. Shilova, L. A. Yakunin. Applied Mechanics and Materials, 587-589, 565-572 (2014)

13. Tchobanoglous, G., Burton, F.L. Wastewater Engineering: Treatment, Disposal, Reuse (New York: McGraw-Hill, 1991)

14. L.M. Molodkina, D.D. Kolosova, E.I. Leonova, M.F. Kudoyarov, M.Y. Patrova, Y.V. Vedmetskii. Petroleum Chemistry, 52(7), 487-493 (2012)

15. V.N. Chechevichkin, N.I. Vatin. Applied Mechanics and Materials, 641-642, 409-415 (2014)

16. M.Ju. Andrianova, L.M. Molodkina, E.A. Bondarenko, A.N. Chusov, M.P. Fedorov. Proceedings of CRETE 2014 The International Conference on Industrial and Hazardous Waste Management, 79-80 (2014)

17. M. R. Beychok. Aqueous Wastes from Petroleum and Petrochemical Plants, (John Wiley \& Sons, 1967)

18. A.I. Zouboulis, A. Avranas, Colloids and Surfaces A: Physicochemical and Engineering Aspects 172, 153-161 (2000)

19. M.L.S. Welz, N. Baloyi, D.A. Deglon, Water SA 33(4), 453-458 (2007)

20. W.-S. Ye, J.C. Liang, T.C. Hsu, In Vitro 19(1), 53-57 (1983)

21. M. Schwab, Encyclopedia of Cancer (Springer-Verlag Berlin Heidelberg, 2012) 